\title{
Self Breast Examination: A Tool for Early Diagnosis of Breast Cancer
}

\author{
Saurabh RamBihariLal Shrivastava", Prateek Saurabh Shrivastava, Jegadeesh Ramasamy \\ Department of Community Medicine, Shri Sathya Sai Medical College \& Research Institute, Kancheepuram, India \\ *Corresponding author: drshrishri2008@gmail.com
}

Received June 14, 2013; Revised June 20, 2013; Accepted June 22, 2013

\begin{abstract}
Breast cancer is a global health concern and a leading cause of morbidity and mortality among women. It has been identified as a major public health problem in both developed and developing nations because of its high incidence-prevalence, over-burdened health system and direct medical expenditure. Studies have shown that in most of the developing nations breast cancer is diagnosed in advanced stages of the disease when compared with developed nations and thus has a poor outcome and high fatality rate. This paper aims to check the effectiveness of breast self-examination in early detection of the breast cancer. In addition, it plans to consider all the factors which hampers with the uptake of the technique and what all could be planned to improve the current scenario. An extensive search of all materials related to the topic was made using library sources including Pubmed, Medline and google scholar searches. Keywords used in the search include breast self-examination, barriers in breast selfexamination and breast cancer. Breast self-examination (BSE) has been identified as the only realistic approach in early detection of breast cancer in developing nations. A wide knowledge-application gap has been observed across the globe between the knowledge and the actual practice of BSE. Multiple socio-demographic factors, myths, cultural beliefs, lack of accessibility to the health care services have been identified as the reasons for the poor uptake of BSE. Considering the potential of BSE, there is an immense need for a public health education program to inculcate the practice of breast self-examination among women to minimize the fear, denial, myths and misconceptions. This requires a sustained political commitment and further studies to recognize the perceived barriers which are interfering with the uptake of BSE so that the greatest challenge of late presentation can be curbed and the chances of survival improved.
\end{abstract}

Keywords: breast cancer, breast self-examination, risk factors, screening, awareness

\section{Introduction}

Breast cancer is a global health concern and a leading cause of morbidity and mortality among women [1,2,3,4]. It has been identified as a major public health problem in both developed and developing nations because of its high incidence-prevalence, over-burdened health system and added direct medical expenditure $[5,6,7,8]$. Trend analysis of breast cancer indicates a rise by $50-100 \%$ in the incidence of breast cancer in last 20 years [9]. Breast cancer in men is uncommon, accounting for less than $1 \%$ of all breast cancers but rise in incidence of male breast cancer has also been demonstrated [10,11]. Breast cancer can be distinguished from other cancers by the fact that it occurs at a site which can be easily noticed and thus liable for early detection \& treatment [12]. The incidence, mortality and survival rates for breast cancer vary across the globe because of underlying differences in known risk factors, availability of organized screening programs and access to effective and affordable treatment modalities [1]. However, fatality rates tend to be higher in low-resource countries [13,14].

Breast cancer associated morbidity and mortality can be reduced through early detection by means of screening programs [15], as it not only increases the chances for successful treatment and cure of the disease $[16,17]$, but also improves chances of survival and lessens the need of invasive treatment [18]. Ensuring availability of early diagnostic \& screening services and taking immediate steps have been regarded as the two main strategies for warranting improvement in the prognostic outcome $[19,20,21]$.

Studies have shown that in contrast to the developed nations most of the developing nations have recorded a poor outcome and high fatality rate owing to diagnosis of the breast cancer in advanced stages [22,23,24,25,26,27,28]. In-fact, in a study done in India, five-year survival rate was $56 \%$ among patients diagnosed with breast cancer at a later stage in comparison to $85 \%$ for cases diagnosed early [29]. Implementation of the preventive measures has been acknowledged as the main tool in the fight against breast cancer worldwide. Globally, breast self-examination (BSE), clinical breast examination (CBE) and mammography are the recommended screening test for early detection of breast cancer. Due to lack of access to diagnostic facilities, especially for women in low resource settings, it is essential to empower them with BSE as a primary modality for screening [28,30]. This review article aims to review the effectiveness of breast selfexamination in early detection of the breast cancer. In 
addition, it plans to consider all the factors which hampers with the uptake of the technique and what all could be planned to improve the current scenario.

\section{Materials and Methods}

An extensive search of all materials related to the topic was made using library sources including Pubmed, Medline, World Health Organization website and Google scholar searches for one month. Relevant documents, technical publications series, systematic reviews, research articles focusing on practice of breast self-examination published in the period 1980 - 2013 were included for the review. The identified articles were then re-grouped into different sections viz. risk factors and clinical features of breast cancer; significance of breast self-examination; practice of breast self-examination; impact of sociodemographic factors on performance of breast selfexamination; role of nurses' in advocating breast selfexamination; impediments in breast self-examination; and implications for practice and research. Keywords used in the search include breast self-examination, barriers in breast self-examination and breast cancer.

\section{Breast Cancer: Risk Factors and Clinical Features}

The etiology of breast cancer is multi-factorial and studies have revealed significant interaction between endogenous (hormonal / genetic) and exogenous (drugs / radiation) factors [31]. Other factors like women's age [32,33]; parity [34]; practice of late initiation of breastfeeding [34,35]; oral contraceptives \& hormone replacement therapy [31,33,36]; high dietary fat, excessive alcohol consumption, positive family history [33]; age at menarche, menopausal status, age at first live birth, genetic mutations and benign breast disease have also been cited $[37,38,39,40]$. With regards to symptoms of breast cancer, bloody discharge from the nipple and presence of lump in breast are well known [41].

\section{Breast Self-examination: Background}

Early diagnosis of breast cancer is of extreme significance in improving the survival rates and quality of life especially in low-income countries [42]. Although awareness about breast cancer has long been advocated across the world, unfortunately studies have revealed that a major proportion of women are still not breast aware [41,43]. As discussed earlier, techniques such as breast self-examination (BSE), clinical breast examination (CBE) and mammography have been advocated for bringing about a marked reduction in breast cancer associated morbidity and mortality $[44,45,46,47,48]$. As compared to $\mathrm{CBE}$ and mammography which require hospital visit and specialized equipment / technical expertise, BSE is helpful in the regard that it is cost-free, simple, non-invasive intervention carried out by women themselves [4,49,50].

Studies conducted in developing countries have established BSE as one of the most reasonable and feasible approach in early detection of breast cancer
[51,52,53]. BSE not only familiarize women with the appearance/feel of their breast but also aids in early detection of breast cancer [30]. Some of the studies have reported that BSE is highly effective in increasing sense of ownership about health, healthcare seeking behavior, encouraging adoption of preventive health behaviors and creating awareness about breast cancer among women [54,55]. Multiple studies have concluded that women, who regularly perform breast self-examination present with smaller neoplasm and rare involvement of axillary lymph nodes [29,30,56,57,58,59]. On the other hand, some researchers have seriously questioned the usefulness of BSE [60,61], while others have revealed no added benefits of BSE in improvement of survival rates $[62,63]$.

\section{Practice of Breast Self-examination}

With the rising incidence of breast cancer and absence of any uniform breast screening strategy in most of the nations, it is important to assess the knowledge and practice of BSE in various age groups. Irrespective of the multiple benefits of BSE, various studies identified a wide knowledge application gap with regards to BSE, the practice of BSE remaining low and variable in different nations like 54\% in England [59]; varying from 19\% to $43.2 \%$ in Nigeria [50,64], and varying from 0 to $52 \%$ in India $[29,65]$. In a study done in Korea, $27 \%$ of students were engaged in BSE which was higher than what was observed in students (10.1\%) from Nigeria [66,67].

Among the health-care providers, around $90.3 \%$ women performed BSE in Sao Paulo [68]; while in Turkey 28\% of the nurses and $32 \%$ of physicians did not practice BSE [69]. Similarly, in a cross-sectional study conducted in Iran it was revealed that most of the female health care workers (63-72\%) did not practice BSE [70]. Studies done with an aim to assess the knowledge about BSE among men have shown low level of knowledge [71,72]. This was mainly because most of the pamphlets and information-education-counseling materials usually deals only with women's breast cancer related issues [71,72].

\section{Impact of Socio-Demographic Parameters on Breast Self-examination}

Studies have indicated that major proportion of the women are not aware of what they need to do to protect themselves from breast cancer or even how to check themselves [73,74]. Further it has been reported that older age ( $>45$ years) and married women were more likely to practice BSE than others [54,75]. In a study done in Turkey, significant association was observed between breast cancer knowledge and practice of BSE [54]. In addition, women with a positive family history of breast cancer had a better knowledge as well as higher frequency of BSE than those with a negative family history [74,76]. The importance of education in the adoption of BSE practice has been reported repeatedly $[75,77,78]$. Simultaneously the positive impact of educational interventions on BSE and breast cancer awareness have also been emphasized [79,80]. 


\section{Role of Nurses' in Breast Self- examination}

Health care providers, educational institutions and mass-media are the important resources in dissemination of any public health related information to masses. The nursing staff can play a pivotal role in educating women through specially designed learning programs in the health care setting, as well as, through community outreach approaches that suit the social and cultural settings [81]. A study done in Turkey emphasized that nurses' opinion about breast cancer screening programs was crucial in developing breast cancer educational programs [78]. It has been reported that nurses who own adequate knowledge about breast cancer can definitely contribute towards early detection of breast cancer $[82,83]$. It has been realized that nurses have an indispensible role in teaching women in the community and in influencing their behavior, especially those working in the rural healthcare set-up [12].

\section{Barriers to Breast Self-examination}

Though breast self-examination is considered an important tool in early detection of breast cancer, multiple barriers have been identified viz. awareness about breast cancer $[52,54,77,84]$; lack of time, shortage of selfconfidence, fear of possible detection of a mass and feeling of awkwardness about breast handling [85]; health related assumptions [86]; anxiety and forgetfulness $[29,87]$; low socioeconomic status and poor access to health care facilities [88]; negative socio-cultural perception about breast cancer and strong belief in traditional medicine[89], and lack of motivational support from parents, spouse or friends [90].

\section{Implications for Practice}

There is an immense need for a public health education program to inculcate the practice of breast selfexamination among women to minimize the fear, denial, myths and misconceptions. The messages and recommendations about breast cancer screening must be clear and the recognized barriers should be taken into consideration for maximization of the outcome. Every effort has to be taken to encourage the practice of BSE not only among women but also among men as there is visible increase in the incidence of male breast cancer. Healthcare professionals including grass root level health workers have to play a significant role in educating the public especially the high risk men \& women. The involvement of community, family especially parents and spouse should be facilitated to maximize the understanding of BSE. Non-governmental organizations can be roped in rural areas for this initiative. Concurrently, family physicians should be encouraged to raise awareness; offer clear and specific instructions on practice of breast selfexamination and promote referral as well.

\section{Implications for Research}

It is essential to plan and conduct community-based studies to find the knowledge, attitude and practices of BSE among both women and men as it will aid in identification of the perceived barriers. Further studies are needed to explore what customized interventions could be implemented to improve the uptake and practice of BSE and other methods for early breast cancer detection. Results derived from these studies will help the program managers and healthcare professionals to modify / emphasize / strengthen the existing strategies so that the greatest challenge of late presentation can be curbed and the chances of survival improved.

\section{Conclusion}

Breast self-examination has been identified as the only feasible and reasonable approach in early detection of breast cancer especially in developing nations. Considering the substantial role that can be played by BSE in low resource settings, there is an urgent need for interventions to implement and reinforce BSE in the existing cancer awareness and screening programs. Also, to bridge the wide knowledge - application gap, health education and awareness campaigns should be organized to empower the public on the causes, risk factors and prevention of breast cancer.

\section{References}

[1] Althuis, M.D., Dozier, J.M., Anderson, W.F., Devesa, S.S. and Brinton, L.A, "Global trends in breast cancer incidence and mortality 1973-1997,” Int J Epidemiol, 34 (2), 405-12, 2005.

[2] Shibuya, K., Mathers, C.D., Boschi-Pinto, C., Lopez, A.D. and Murray, C.J, "Global and regional estimates of cancer mortality and incidence by site: II. Results for the global burden of disease 2000," BMC Cancer 2, 37, 2002.

[3] Hortobagyi, G.N., de la Salazar, G.J., Pritchard, K., Amadori, D., Haidinger, R., Hudis, C.A., Khaled, H., Liu, M.C., Martin. M., Namer, M., O'Shaughnessy, J.A., Shen, Z.Z., Albain, K.S. and ABREAST Investigators, "The global breast cancer burden: Variations in epidemiology and survival," Clin Breast Cancer, 6 (5), 391-401, 2005.

[4] Jemal, A., Bray, F., Center, M.M., Ferlay, J., Ward, E. and Forman, D, "Global cancer statistics," CA Cancer J Clin, 61 (2), 69-90, 2011.

[5] Parkin, D.M., Bray, F., Ferlay, J. and Pisani, P, “Global cancer statistics, 2002” CA Cancer J Clin, 55 (2), 74-108, 2005.

[6] Rastgoi, M, Increase in cancer death by the year 2020, Geneva: World Health Organization, 2004.

[7] Forbes, J.F, "The incidence of breast cancer: The global burden, public health considerations," Semin Oncol, 24 (1 Suppl 1), S2035, 1997.

[8] Bray, F., Ren, J.S., Masuyer, E. and Ferlay, J, “Global estimates of cancer prevalence for 27 sites in the adult population in 2008," Int J Cancer 132 (5), 1133-1145, 2013.

[9] Salem, O.A. and Hassan, M.A, "Breast self-examination among female nurses” Rawal Med J, 32 (1), 31-33, 2007.

[10] Giordano, S.H., Cohen, D.S., Buzdar, A.U., Perkins, G. and Hortobagyi, G.N, "Breast carcinoma in men: a population based study” Cancer, 101 (1), 51-57, 2004.

[11] Stang, A. and Thomssen, C, "Decline in breast cancer incidence in the United States: what about male breast cancer?,” Breast Cancer Research and Treatment, 112 (3), 595-596, 2008.

[12] Tasci, A. and Usta, Y.Y, "Comparison of knowledge and practices of breast self-examination: A pilot study in Turkey" Asian Pac $J$ Cancer Prev, 11 (5), 1417-1420, 2010.

[13] EMRO Technical Publications Series, 30 WHO: Guidelines for the early detection and screening of breast cancer, World health 
organization regional office for the Eastern Mediterranean, Cairo, 2006.

[14] Hallal, J.C, "The relationship of health beliefs, health locus of control, and self concept to the practice of breast self-examination in adult women,” Nurs Res, 31 (3), 137-142, 1982.

[15] Austoker, J., Bankhead, C., Forbes, L.J., Atkins, L., Martin, F., Robb, K., Wardle, J. and Ramirez, A.J, "Interventions to promote cancer awareness and early presentation: systematic review,” $\mathrm{Br} J$ Cancer, 101 (Suppl 2), S31-39, 2009.

[16] Chong, P.N., Krishnan, M., Hong, C.Y. and Swah, T.S, "Knowlegde and practice of breast cancer screening amongst public health nurses in Singapore,” Singapore Med J, 43 (10), 509-516, 2002.

[17] Harmer, V, "Breast cancer. Part 1: Awareness and common benign diseases,” Br J Nurs, 17 (15), 950-955, 2008.

[18] Noel, A., Heid, P., Tardivon, A., Dilhuydy, M.H., Haber, S., Seradour, B and Groupe technique national sur le dépistage du cancer du sein, "Screening mammography of women with a hereditary predisposition to cancer of the breast," Bull Cancer, 91 (7-8), 655-656, 2004.

[19] Burgess, C.C., Linsell, L., Kapari, M., Omar, L., Michell, M., Whelehan, P., Richards, M.A and Ramirez, A.J, "Promoting early presentation of breast cancer by older women: A preliminary evaluation of a one-to-one health professional-delivered intervention,” J Psychosomatic Res, 67 (5), 377-387, 2009.

[20] Abulkhair, O.A., Al Tahan, F.M., Young, S.E., Musaad, S.M. and Jazieh, A.R, "The first national public breast cancer screening program in Saudi Arabia,” Ann Saudi Med, 30 (5), 350-357, 2010.

[21] Forbes, L.J., Linsell, L., Atkins, L., Burgess, C., Tucker, L., Omar, L., Ramirez, A.J, “A promoting early presentation intervention increases breast cancer awareness in older women after 2 years: a randomised controlled trial,” Br J Cancer, 105 (1), 18-21, 2011.

[22] Elmore, J.G., Armstrong, K., Lehman, C.D. and Fletcher, S,W, "Screening for breast cancer," JAMA, 293 (10), 1245-1256, 2005.

[23] Harirchi, I., Kolahdoozan, S., Karbakhsh, M., Chegini, N., Mohseni, S.M., Montazeri, A., Momtahen, A.J., Kashefi, A. and Ebrahimi, M, “Twenty years of breast cancer in Iran: downstaging without a formal screening program,” Ann Oncol, 22 (1), 93-97, 2011.

[24] Ertem, G. and Kocer, A, "Breast self-examination among nurses and midwives in Odemis health district in Turkey," Indian $J$ Cancer, 46 (3), 208-213, 2009.

[25] Sadjadi, A., Nouraie, M., Ghorbani, A., Alimohammadian, M. and Malekzadeh, R, "Epidemiology of breast cancer in the Islamic Republic of Iran: first results from a population-based cancer registry,” East Mediterr Health J, 15 (6), 1426-1431, 2009.

[26] Adesunkanmi, A.R., Lawal, O.O., Adelusola, K.A. and Durosimi, M.A, "The severity, outcome and challenges of breast cancer in Nigeria,” Breast, 15 (3), 399-409, 2006.

[27] Hisham, A.N. and Yip, C.H, "Overview of breast cancer in Malaysian women: a problem with late diagnosis,” Asian J Surg, 27 (2), 130-133, 2004.

[28] Coughlin, S.S. and Ekwueme, D.U, "Breast cancer as a global health concern,” Cancer Epidemiol, 33 (5), 315-318, 2009.

[29] Gupta, S.K, "Impact of a health education intervention program regarding breast self-examination by women in a semi-urban area of Madhya pradesh, India,” Asian Pac J Cancer Prev, 10 (6), 1113-1117, 2009.

[30] Karayurt, O., Ozmen, D. and Çetinkaya, A.C, “Awareness of breast cancer risk factors and practice of breast self-examination among high school students in Turkey,” BMC Public Health, 8, 359, 2008.

[31] Kahlenborn, C., Modugno, F., Potter, D.M. and Severs, W.B, "Oral contraceptive use as a risk factor for premenopausal breast cancer: a meta-analysis,” Mayo Clin Proc, 81 (10), 1290-1302, 2006.

[32] Rosner, B., Colditz, G.A. and Willett, W.C, "Reproductive risk factors in a prospective study of breast cancer: The nurses' health study,” Am J Epidemiol, 139 (8), 819-835, 1994.

[33] Downs-Holmes, C., Silverman, P, "Breast cancer: Overview \& updates,” The Nurse Practitioner, 36 (12), 20-26, 2006.

[34] Collaborative group on hormonal factors in breast cancer, "Breast cancer and breastfeeding: Collaborative reanalysis of individual data from 47 epidemiological studies in 30 countries, including 50302 women with breast cancer and 96973 women without the disease,” Lancet, 360 (9328), 187-195, 2002.

[35] Puri, S., Mangat, C., Bhatia, V., Kalia, M., Sehgal, A. and Kaur, A.P, "Awareness of risk factors and aspects of breast cancer among north Indian women,” The Internet Journal of Health, 8, 2 2009.

[36] Somdatta, P. and Baridalyne, N, "Awareness of breast cancer in women of an urban resettlement colony,” Indian $J$ of Cancer, 45 (4), 149-153, 2008.

[37] Veronesi, U., Boyle, P., Goldhirsch, A., Orecchia, R. and Viale, G, “Breast cancer,” Lancet, 365 (9472), 1727-1741, 2005.

[38] Lee, S.M., Park, J.H. and Park, H.J, "Breast cancer risk factors in Korean women: a literature review,” Int Nurs Rev, 55 (3), 355-359, 2008.

[39] Thomsen, A. and Kolesar, J.M, "Chemoprevention of breast cancer,” Am J Health Syst Pharm, 65 (23), 2221-2228, 2008.

[40] Dandash, K.F. and Al-Mohaimeed, A, "Knowledge, attitudes, and practices surrounding breast cancer and screening in female teachers of Buraidah, Saudi Arabia,” Int J Health Sci (Qassim), 1 (1), 61-71, 2007.

[41] Kanaga, K.C., Nithiya, J. and Shatirah, M.F, “Awareness of breast cancer and screening procedures among Malaysian women," Asian Pacific J Cancer Prev, 12 (8), 1965-1967, 2011.

[42] Rao, R., Nair, S., Nair, N. and Kamath, V, “Acceptability and effectiveness of a breast health awareness programme for rural women in India,” Indian J Med Sci, 59 (9), 398-402, 2005.

[43] Wu, T.Y., West, M.A., Chen, Y.W. and Hergert, C, "Health beliefs and practices related to breast cancer screening in Filipino, Chinese and Asian-Indian women," Cancer Detect Prev, 30 (1), 58-66, 2006.

[44] Omar, S., Khaled, H., Gaafar, R., Zekry, A.R., Eissa, S. and ElKhatib, O, "Breast cancer in Egypt: A review of disease presentation and detection strategies," East Mediterr Health J, 9 (3), 448-463, 2003.

[45] Humphrey, L.L., Helfand, M., Chan, B.K. and Woolf, S.H, "Breast cancer screening: A summary of the evidence for the U.S. Preventive Services Task Force,” Ann Intern Med, 137 (5 Part 1), 347-360, 2002.

[46] Avcı, A.I., Altay, B. and Kocaturk, B, “Midwifery students' health beliefs intended for breast self-examination," J Breast Health, 4 (1), 25-28, 2008.

[47] Gerçek, S., Duran, O., Yıldırım, G., Karayel, H. and Demirliçakmak, D, "Determining the breast cancer and self breast examination belief and the effecting factors among the schoolgirls in state dormitory,” J Breast Health, 4 (3), 157-161, 2008.

[48] Ertem, G. and Koçer, A, "Breast self-examination among nurses and midwives in Odemiş district in Turkey,” Indian J Cancer, 46 (3), 208-213, 2009.

[49] World Health Organization, Breast cancer: prevention and control 2013. Available: http://www.who.int/cancer/detection/breastcancer/en/print.html. [ Accessed May 24, 2013].

[50] Okobia, M.N., Bunker, C.H., Okonofua, F.E. and Osime, U, "Knowledge, attitude and practice of Nigerian women towards breast cancer: A cross-sectional study,” World J Surg Oncol, 4, 11, 2006.

[51] Mittra, I., Baum, M., Thornton, H. and Houghton, J, "Is clinical breast examination an acceptable alternative to mammographic screening?,” BMJ, 321 (7268), 1071-1073, 2000.

[52] Dundar, P.E., Ozmen, D., Ozturk, B., Haspolat, G., Akyıldız, F., Çoban, S. Cakiroglu, G, "The knowledge and attitudes of breast self-examination and mammography in a group of women in a rural area in western Turkey,” BMC Cancer, 6, 43, 2006.

[53] Parvani, Z, "Breast self-examination: Breast awareness and practices of systematic review,” Professional Med J, 18, 336-339, 2011.

[54] Austoker, J, “Breast self-examination,” BMJ, 326, 1-2, 2003.

[55] Manasciewicz, R, "Breast self-examination. Editorial misses central point,” BMJ, 326, 710, 2003.

[56] Alexanian, A.A., Fossati, R., Apalone, G., Liberati, A. and Zola, P, "Practice of breast self-examination: disease extent at diagnosis and patterns of surgical care. A report from an Italian study," $J$ Epidemiol Community Health, 45 (2), 112-116, 1991.

[57] Mant, D., Vessey, M.P. and Neil, A, "Breast self-examination and breast cancer stage at diagnosis,” British Journal of Cancer, 55 (2) 207-211, 1987.

[58] Smith, R.A., Mettlin, C.J., Davis, K.J. and Eyre, H, “American Cancer Society guidelines for the early detection of cancer," $C A$ Cancer J Clin, 50 (1), 34-49, 2000.

[59] Philip, J., Harris, W.G., Flaherty, C. and Joslin, C.A, “Clinical measures to assess the practice and efficiency of breast selfexamination," Cancer, 58 (4), 973-977, 1986. 
[60] Kearney, A.J. and Murray, M, "Evidence against breast selfexamination is not conclusive: what policymakers and health professionals need to know," J Public Health Policy, 27 (3), 282292, 2006.

[61] Thomas, D.B., Gao, D.L., Ray, R.M., Wang, W.W., Allison, C.J., Chen, F.L., Porter, P., Hu, Y.W., Zhao, G.L., Pan, L.D., Li, W., Wu, C., Coriaty, Z., Evans, I., Lin, M.G., Stalsberg, H. and Self, S.G, "Randomized trial of breast self-examination in Shanghai: final results,” J Natl Cancer Inst, 94 (19), 1445-1457, 2002.

[62] Kosters, J.P. and Gotzsche, P.C, "Regular self-examination or clinical examination for early detection of breast cancer," Cochrane Database Syst Rev, 2: CD003373, 2003.

[63] Nelson, H.D., Tyne, K., Naik, A., Bougatsos, C., Chan, B., Nygren, P. and Humphrey, L, Screening for breast cancer: Systematic evidence review update for the US Preventive Services Task Force [Online]. Available: http://www.ncbi.nlm.nih.gov/pubmed/20722173 [Accessed May 19, 2013].

[64] Gwarzo, U.M., Sabitu, K. and Idris, S.H, "Knowledge and practice of breast-self-examination among female undergraduate students of Ahmadu Bello University Zaria, northwestern Nigeria," Ann Afr Med, 8 (1), 55-58, 2009.

[65] Yadav, P. and Jaroli, D.P, "Breast cancer: Awareness and risk factors in college-going younger age group women in Rajasthan," Asian Pac J Cancer Prev, 11 (2), 319-322, 2010.

[66] Shin, K.R., Park, H.J. and Kim, M, "Practice of breast selfexamination and knowledge of breast cancer among female university students in Korea," Nurs Health Sci, 14 (3), 292-297, 2012.

[67] Isara, A.R. and Ojedokun, C.I, "Knowledge of breast cancer and practice of breast self-examination among female senior secondary school students in Abuja, Nigeria," J Prev Med Hyg, 52 (4), 186190, 2011.

[68] Carelli, I., Pompei, L.M., Mattos, C.S., Ferreira, H.G., Pescuma, R., Fernandes, C.E. and Peixoto, S, "Knowledge, attitude and practice of breast self-examination in a female population of metropolitan Sao Paulo," Breast, 17 (3), 270-274, 2008.

[69] Cavdar, Y., Akyolcu, N., Ozbaş, A., Oztekin, D., Ayogu, T. and Akyuz, N, 'Determining female physicians' and nurses' practices and attitudes toward breast self-examination in Istanbul, Turkey," Oncol Nurs Forum, 34 (6), 1218-1221, 2007.

[70] Haji-Mahmoodi, M., Montazeri, A., Jarvandi, S., Ebrahimi, M., Haghighat, S. and Harirchi, I, "Breast self-examination: Knowledge, attitudes, and practices among female health care workers in Tehran, Iran,” Breast J, 8 (4), 222-225, 2002.

[71] Thomas, E, "Men's awareness and knowledge of male breast cancer," Am J Nurs, 110 (10), 32-40, 2010.

[72] Al-Naggar, R.A. and Al-Naggar, D.H, "Perceptions and opinions about male breast cancer and male breast self-examination: A qualitative study,” Asian Pac J Cancer Prev, 13 (1), 243-246, 2012.

[73] Al-Naggar, R.A., Al-Naggar, D.H., Bobryshev, Y.V., Chen, R. and Assabri, A, "Practice and barriers toward breast selfexamination among young Malaysian women," Asian Pac J Cancer Prev, 12 (5), 1173-1178, 2011.

[74] Koşgeroglu, A., Ayranc1, U. and Ozerdogan, N, "Knowledge of women on early diagnosis methods and risk factors for breast cancer in a province of Western Turkey: a descriptive study,” Pak J Med Sci, 27, 646-650, 2011.

[75] Ravichandran, K., Al-Hamdan, N.A. and Mohamed, G, "Knowledge, attitude, and behavior among Saudis toward cancer preventive practice,” J Family Community Med, 18 (3), 135-142, 2011.

[76] Karayurt, O. and Zorukoş, S.N, "Feel of women at a high risk for breast cancer and meeting, their needs for knowledge and support" J Breast Hlth, 4 (2), 56-61, 2008.

[77] Rasu, R.S., Rianon, N.J., Shahidullah, S.M., Faisel, A.J. and Selwyn, B.J, "Effect of educational level on knowledge and use of breast cancer screening practices in Bangladeshi women," Health Care Women Int, 32 (3), 177-189, 2011.

[78] Ceber, E., Turk, M. and Ciceklioglu, M, "The effects of an educational program on knowledge of breast cancer, early detection practices and health beliefs of nurses and midwives," $J$ Clin Nurs, 19(15-16), 2363-2371, 2010.

[79] Yavari, P. and Pourhoseingholi, M.A, "Socioeconomic factors association with knowledge and practice of breast selfexamination among Iranian women," Asian Pac J Cancer Prev, 8 (4), 618-622, 2007.

[80] Venkatramana, M., Sreedharan, J., Muttappallymyalil, J. and Thomas, M, "Opinion of nurses regarding breast cancer screening programs," Indian J cancer, 48 (4), 423-427, 2011.

[81] Nichols, M, "The nurse's role in self-breast examination education,” Plast Surg Nurs, 32 (4), 143-145, 2012.

[82] Lee, S.O., Sim, S. and Ahn, S, "Factors affecting periodic screening behaviors for breast cancer among hospital nurses," Korean J Women Health Nurs, 16 (4), 390-398, 2010.

[83] Dunn, R.A. and Tan, A.K, "Utilization of breast cancer screening methods in a developing nation: results from a nationally representative sample of Malaysian households," Breast J, 17 (4), 399-402, 2011.

[84] Alwan, N.A., Al-Attar, W.M., Eliessa, R.A., Madfaie, Z.A. and Tawfeeq, F.N, "Knowledge, attitude and practice regarding breast cancer and breast self-examination among a sample of the educated population in Iraq,” East Mediterr Health J, 18 (4), 337345, 2012.

[85] Brewer, M.K. and Baldwin, D, "The relationship between selfesteem, health habits, and knowledge of BSE practice in female inmates," Public Health Nurs, 17 (1), 16-24, 2000.

[86] Eroglu, N.U. and Kilic, D, "Knowledge, attitude and beliefs women attending mammography units have regarding breast cancer and early diagnosis," Asian Pac J Cancer Prev, 12 (7), 1855-1860, 2011.

[87] Tang, T.S., Solomon, L.J. and McCracken, L.M, “Cultural barriers to mammography, clinical breast exam, and breast self-exam among Chinese-American women 60 and older," Prev Med, 31 (5); 575-583, 2000.

[88] Aziz, Z., Sara, S., Akram. M. and Saeed, A, "Socioeconomic status and breast cancer survival in Pakistani women," J Pak Med Assoc, 54 (9), 448-453, 2004.

[89] Odusanya, O.O. and Tayo, O.O, "Breast cancer knowledge attitudes and practice among nurses in Lagos, Nigeria," Acta Oncol, 40 (7), 844-848, 2001.

[90] Rosmawati, N.H, "The usage and knowledge of mammography among women in sub-urban area in Terengganu, Malaysia,” Asian Pac J Cancer Prev, 11 (3), 767-771, 2010. 